\title{
Increasing the performances of various Types Outdoor Insulators by using RTV Silicone Rubber Coating
}

\author{
Suwarno and Ario Basuki Wibowo \\ School of Electrical Engineering and Informatics, Institut Teknologi Bandung \\ Jl. Ganesha 10 Bandung, INDONESIA \\ suwarno@ieee.org
}

\begin{abstract}
Insulator is one of the most important equipments in an electric power system. Since long time ago ceramic insulators are widely used in transmission as well as in distribution lines. As outdoor insulators, the insulators are subjected to outdoor environmental stresses such as humidity, temperature and pollution. Under polluted and wet condition, high leakage current may flow on the insulator surface. As the result a dry band arching may take place and in the long time it may degrade the insulator and initiate the insulator flash over leading to the failure of the lines. Several efforts may be taken to improve the insulator performance under polluted condition. They are increasing the number of insulator strings, modification of insulator design to increase the creep age distance and regular washing. This paper presents the investigation $\backslash$ results on the silicone coating on ceramic insulators under laboratory and real environmental conditions. It was found that the coating was significantly suppressed the magnitude of leakage current and drastically eliminated the harmonic content. The coating also drastically suppressed the corona on the insulator and reduced the surface temperature. The coating also significantly increased the flash over voltage of the insulator. Leakage current analysis and simulation showed significant improvement of surface resistance of insulator after application of RTV coating under most environmental conditions compared to those of uncoated insulators. Overall investigation results indicated significant improvement of insulator performances by applying RTV silicone rubber coating.
\end{abstract}

Keywords: Performance, outdoor insulator, RTV, silicone rubber coating, leakage current, flashover

\section{Introduction}

The electrical energy demand is increasing steadily. For transmitting a huge amount of electrical energy high voltage transmission system has been widely used. In the transmission system high voltage equipments such as transformers and insulators play important roles. For obtaining normal operation of the power delivery it is necessary to maintain the insulation in the equipments. Ceramic insulators are widely used at substations, transmission and distribution network as well [1]. Outdoor insulators are exposed to environmental climate such as high temperature and humidity as well as pollution from coast and industries. As the result, leakage current may flow on the insulator surface and may degrade the insulator surface[2]. Under particular condition, dry band arcing may take place on the insulator surface leading to the failure of the insulators[3-5].

There are three solutions introduced to solve the environmental problem on the insulator surface. They are periodic washing of insulators, improvement of insulator design and coating with water-repellent agents.

This paper reports the experimental results on the characteristics improvements of various types ceramic insulators by using RTV silicone coating under artificial and natural environments.

Received: August $20^{\text {th }}, 2012$. Accepted: November $15^{\text {th }}, 2012$ 


\section{Experiment}

\section{A. Samples}

There were 4 kinds of insulators used in the experiment. The first insulator was $20 \mathrm{kV}$ class pin-post type ceramic insulators. The insulators has creep age distance of $500 \mathrm{~mm}$. The insulators are widely used in Indonesian electricity network.

Table 1. Samples used in Experiment

\begin{tabular}{|l|l|}
\hline \multicolumn{1}{|c|}{ Sample } & \multicolumn{2}{|c|}{ Pictures } \\
Post-pin type \\
insulator \\
$20 \mathrm{kV}$ application
\end{tabular}

The second insulator was suspension type with creep age distance of $315 \mathrm{~mm}$. The insulators are widely used for $500 \mathrm{kV}$ transmission line insulator strings. The uncoated and 
coated insulator pictures are shown in figure 2 . The $3^{\text {rd }}$ sample was rod type insulator used at $150 \mathrm{kV}$ transmission as shown in figure 3. The rod type insulators were installed in $150 \mathrm{kV}$ transmission lines at Ketewel coastal area in Bali Island. This area is a heavily coastal polluted area and many insulator flashovers are found in the area. The last sample was coated and non coated insulators aged at Pangandaran sub station. The location is 40' South and 108' East hemisphere and $500 \mathrm{~m}$ from Indonesian ocean. The area is highly salt polluted with high failure rate of high voltage insulators. The samples were coated with room temperature vulcanized (RTV) silicone rubber by using high pressure nozzle with thickness of $0,3 \pm 0,05 \mathrm{~mm}$. The 4 samples are tabulated in table 1 .

\section{B. Artificial Pollution}

To investigate the performance of the silicone compound coating, artificial contamination was applied to the insulators. Artificial pollution was applied in accordance with IEC Standard No. 507 1991[6]. Kaolin of $40 \mathrm{~g}$ was used in every $1 \mathrm{lt}$ water. $\mathrm{NaCl}$ was added to the solution to get the desirable value of conductivity. The dry-clean insulators were dipped upside down in the kaolin/salt slurry and were rotated along the axis to obtain uniform contamination. Then the insulators were dried. The sample was put in a test chamber made from aluminium panel with dimension of $900 \times 900 \times 1200 \mathrm{~mm}^{3}$. An artificial pollution was exposed to the samples in the chamber. The samples were subjected to tests according to IEC 507(1991) (fog chamber test).

\section{Insulator Surface Hidrophobicity}

Hidrophobicity is a measure of the ability of a surface to repel water dropped on the surface. The hidrophobicity of the insulator surface in this experiment was determined by measuring the contact angle $\alpha$. of water on the surface. Water drop of $50 \mu \mathrm{l}$ was put on the insulator surface.

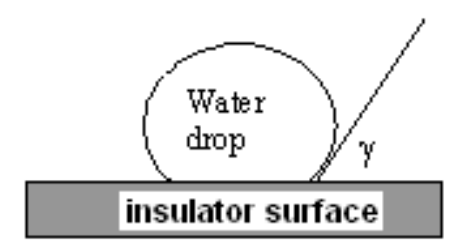

Figure 1. Water drop profile on a surface and contact angle

The water drop profile was taken 2 minutes after the water drop was put on the surface using a camera. The profile of the water drop was taken using a digital camera and the contact angle $\alpha=\left(180^{\circ}-\gamma\right)$ was determined from the image as illustrated in figure 1 .

\section{Corona and temperature measurement}

Corona may occur at a very high electric field spot. Corona may take place on the outdoor surfaces under particular conditions Corona on insulator surface was measured using a Ultra Violet camera Daycor II SN 169. By using this camera the corona intensity can be determined from remote place. The insulator surface was measured using Infra Red Vision camera VISIR. The method was introduced for insulator inspection[7].

\section{E. Leakage Current (LC) and Flashover Voltage Measurements}

High AC voltage of $50 \mathrm{~Hz}$ was applied to the insulators. The leakage current flowed on the insulator surface was measured by measuring the voltage across a series resistance using a Digital Oscilloscope with digitizer of 8 bit, bandwidth of $100 \mathrm{MHz}$, and the maximum sampling rate of $1 \mathrm{GS} / \mathrm{s}$. LC waveforms including low and high frequency components were obtained. The digital data was transferred to a personal computer trough a GPIB for further analysis. The flash over voltage was measured in the same test chamber by increasing the 
applied voltage. Visual observation was done using a video camera. Detail of the measurement was explained elsewhere[8]. Figure 2 shows LC measurement at Pangandaran Sub Station.

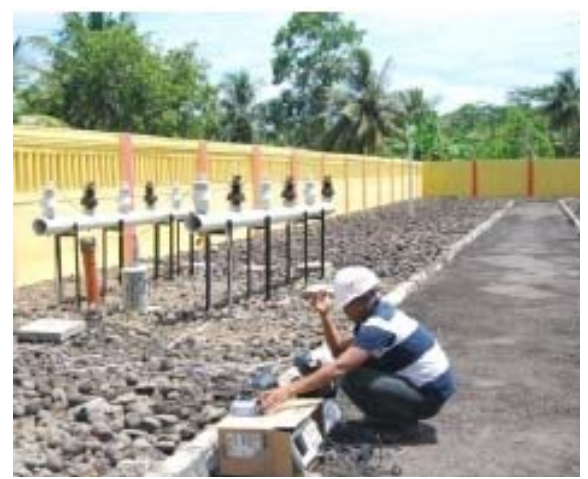

Figure 2. LC measurement on coated and un coated insulators at Pangandaran Sub station

\section{Experimental Results}

A. Leakage current Suppression and flashover voltage Increase

Figure 3 shows the dependence of leakage current for clean and kaolin-salt polluted samples on the applied voltage for post pin type insulators both for TRV coated and non coated insulators. The figure shows that the LC magnitude strongly dependent on the pollution levels and applied voltage. On applied voltage of $10 \mathrm{kV}$, it can be seen that the LC magnitude almost the same for clean sample and kaolin-salt samples. Along with the increasing of applied voltage, the LC magnitude of kaolin sample is higher than the clean sample. Under kaolin salt pollution of $12 \mathrm{mS} / \mathrm{cm}$ non coated insulator flashover at applied voltage of $44 \mathrm{kV}$. However, no flashover was observed for RTV coated insulators even at applied voltage of $60 \mathrm{kV}$. The leakage current was also as low as $1.3 \mathrm{~mA}$ at this voltage level. The magnitude of the leakage current is strongly dependent on the insulator surface condition. The leakage current can be used to monitor the insulator conditions $[9,10]$. The facts also indicate that RTV coating on insulator surface significantly improve the flashover voltage. Therefore, mitigation of insulator flashovers can be done using RTV coating.

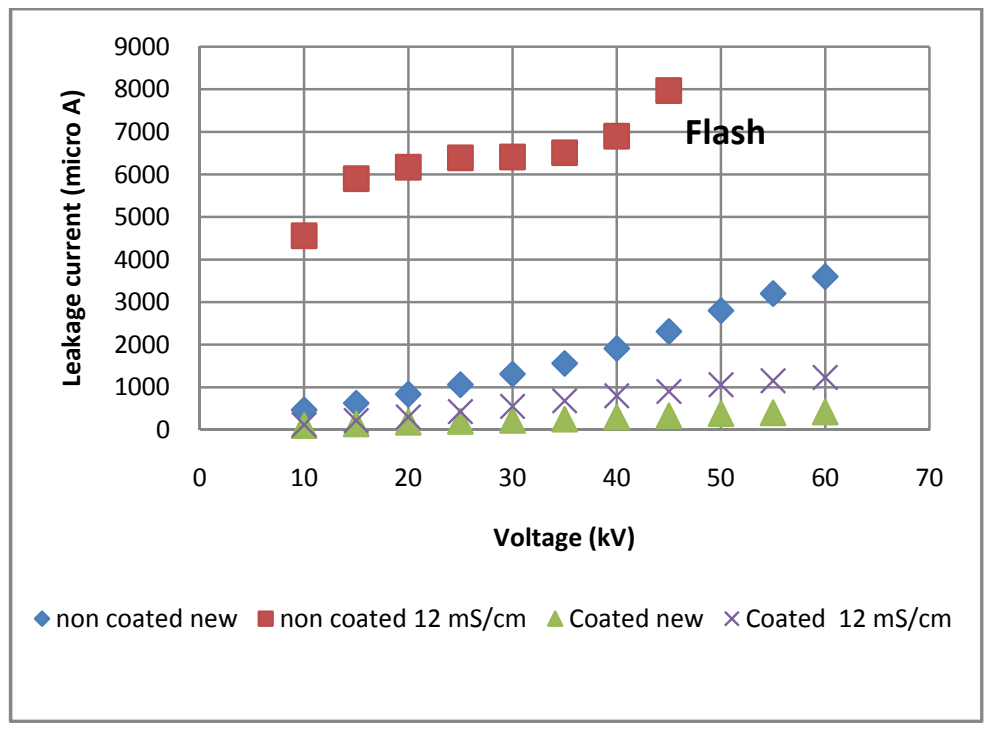

Figure 3. Dependence of leakage current on applied voltage 


\section{B. Hydrophobicity Improvement}

Good outdoor insulators have a strong ability to repel water and pollution from their surfaces. This property is called as Hydrophobicity. Hydrophobicity is indicated by its contact angle. Hydrophobic surface has contact angle more than $90^{\circ}$ while hydrophilic less than $90^{\circ}$. Figure 6 shows photographs of water droplets on uncoated as well as RTV coated insulators surfaces. The water droplet profiles indicates the hydrophobicity of the surfaces.

Table 2 shows typical photographs of water droplets $50 \mu \mathrm{L}$ on clean and kaolin-salt polluted non-coated as well as RTV -coated insulators. The contact angle of the water droplets was measured at 3 minutes after the water droplets were put on the samples.

Table 2. Water Droplet Profile and Contact Angle For Non-Coated and RTV Coated Insulators

\begin{tabular}{|c|c|c|c|}
\hline No & & Water Droplet Profile & $\begin{array}{l}\text { Contact angle } \\
\text { (deg.) }\end{array}$ \\
\hline 1 & $\begin{array}{l}\text { New-non coated clean } \\
\text { insulator- non coated }\end{array}$ & & $45-55$ \\
\hline 2 & $\begin{array}{l}\text { New- coated clean } \\
\text { insulator }\end{array}$ & & $100-110$ \\
\hline 3 & $\begin{array}{l}\text { New-non coated kaolin- } \\
\text { salt polluted }\end{array}$ & & $10-20$ \\
\hline 4 & $\begin{array}{l}\text { New-coated kaolin-salt } \\
\text { polluted }\end{array}$ & & $95-110$ \\
\hline 5 & $\begin{array}{l}\text { RTV Coated insulator } \\
\text { After } 11 \text { months aged at } \\
\text { Pangandaran sub station }\end{array}$ & & $91-100$ \\
\hline 6 & $\begin{array}{l}\text { Uncoated insulator After } \\
11 \text { months aged at } \\
\text { Pangandaran sub station }\end{array}$ & & $35-40$ \\
\hline
\end{tabular}

The table clearly indicates that RTV coating improves the hydrophobicity of new clean insulators significantly from contact angle of $45^{\circ}-55^{\circ}$ to $100^{\circ}-110^{\circ}$. This changes the surface from hydrophilic to hydrophobic. Similarly, RTV silicone rubber coating maintains the hydrophobicity at kaolin-salt pollution with contact angle of $95^{\circ}-110^{\circ}$ which is almost the same value as at clean condition. However, contact angle for non coated insulator drops drastically to is $10^{\circ}-20^{\circ}$ which is a strong hydrophilic surface. For post pin insulators field aged and 
energized at Pangandaran sub station, the contact angle for uncoated insulators dropped from $45-55^{\circ}$ to $35-40^{\circ}$ and became more hydrophylic. This is a significant reduction of hidrophobicity. However, for RTV coated insulators, the contact angle can be maintained at the range of $91-100^{\circ}$ and still highly hydrophobic. The dynamic of the hidrophobicity can be explained in term of the activity of silicone rubber molecules on the insulator surfaces[11,12]

\section{Reduction of Corona intensity and reduction of surface temperature}

Figure 3 shows photographs of rod insulators installed at Ketewel coastal area in Bali. Installed insulators at phase $\mathrm{R}$ and $\mathrm{S}$ are non-coated insulators while for phase $\mathrm{T}$ is RTV silicone rubber- coated insulator. The insulators were installed in February 2009. Corona intensity was measured using UV camera Daycor II SN 169. The count rate indicates the intensity of the corona. The figure shows that the coronas measured for non coated insulators installed at phase $\mathrm{R}$ and $\mathrm{S}$ were at count rate of $3598 / \mathrm{min}$ and $3642 / \mathrm{min}$ respectively. On the other hand corona for RTV silicone rubber coated insulator installed at phase T was $357 / \mathrm{min}$. The results indicate that RTV silicone rubber coating drastically reduces the corona intensity on the insulator surfaces.

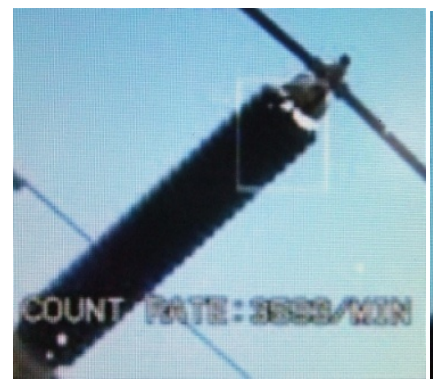

(a)

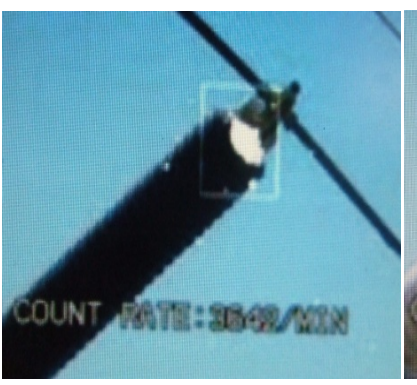

(b)

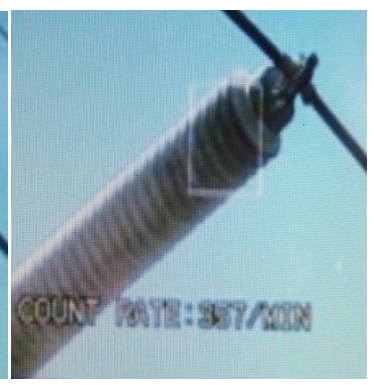

(c)

Figure 3 photographs of rod insulators installed at Ketewel coastal area in Bali (a) phase R (uncoated) (b) phase S (uncoated) and (c) phase T (coated)

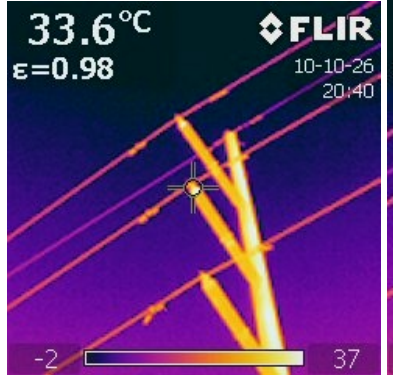

(a)

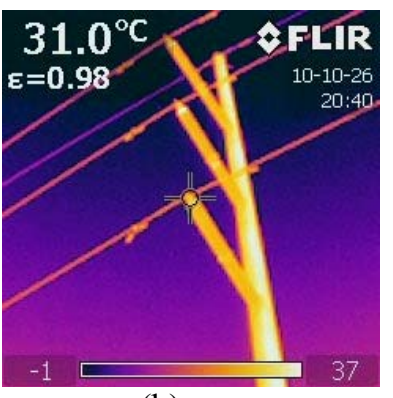

(b)

Figure 4. Surface temperature of (a) uncoated insulator and (b) coated insulator at Ketewel Beach

Figure 4 shows the surface temperature images for uncoated (a) and coated insulator (b). of rod insulator located and energized at Ketewel coast. The temperature of uncoated insulator was about $33.6^{\circ} \mathrm{C}$ while for coated insulator was $31.0^{\circ} \mathrm{C}$. The significant reduction of surface temperature may be due to the reduction of leakage current and due to better thermal properties of RTV compared to those of ceramic surface. The reduction of the temperature may also be attributed to the reduction of corona activity by applying RTV SIR coating. Measurement of insulators after 11 months energized at Pangandaran sub station showed similar results. The temperature of non coating insulators was $31,3{ }^{\circ} \mathrm{C}-36^{\circ} \mathrm{C}$ while for RTV 
coated insulator was $30,9{ }^{\circ} \mathrm{C}-34.1{ }^{\circ} \mathrm{C}$. There is an average different of surface temperature of about $2{ }^{\circ} \mathrm{C}$ between non coated and coated insulator. This is a great considerable improvement.

\section{Leakage current waveforms and computer simulation}

Figure 5 shows typical leakage current waveforms and harmonic components for clean non coated (a) and RTV silicone coated insulator (b) under clean fog and energized at $40 \mathrm{kV}$. The LC waveforms were strongly distorted from their sinusoidal due to presence of harmonic components specially $5^{\text {th }}$ and $7^{\text {th }}$ components as results of the non linearity behaviour of the insulator. The distorted $\mathrm{LC}$ waveform also due to the presence of discharges on the insulator surface especially during dry band arcing[13-15].
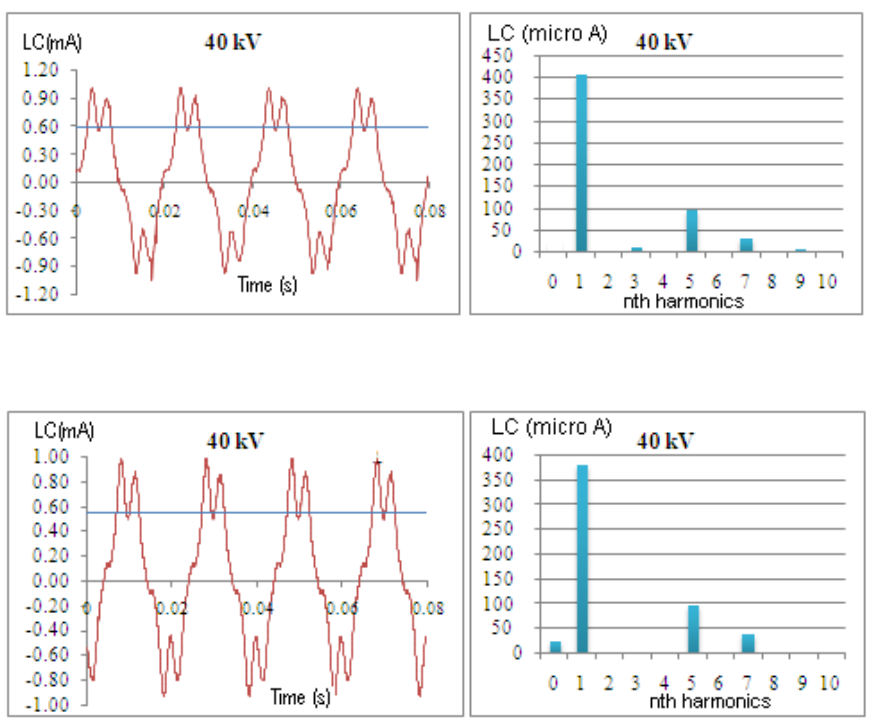

Figure 5. Leakage current waveforms and harmonic contents of clean (a) uncoated and (b) coated insulators under clean fog

In order to obtain deeper understanding of insulator properties and the role of RTV silicone rubber coating, an electrical equivalent circuit model is used. The detail of the modeling of the insulator was explained in [16]. Considering the properties of leakage current waveforms flowed on the suspension high voltage ceramic insulator, the insulator can be represented by resistors, capacitances, non linear capacitors and arcs. Resistors and capacitances represent the bulk properties of the insulator under high voltage. The non linear resistors are the representation of the non linear behaviour of the insulator surface particularly under pollution and high humidity while the arc represents the discharges occur on the insulator surface. The equivalent circuit is shown in figure 6.

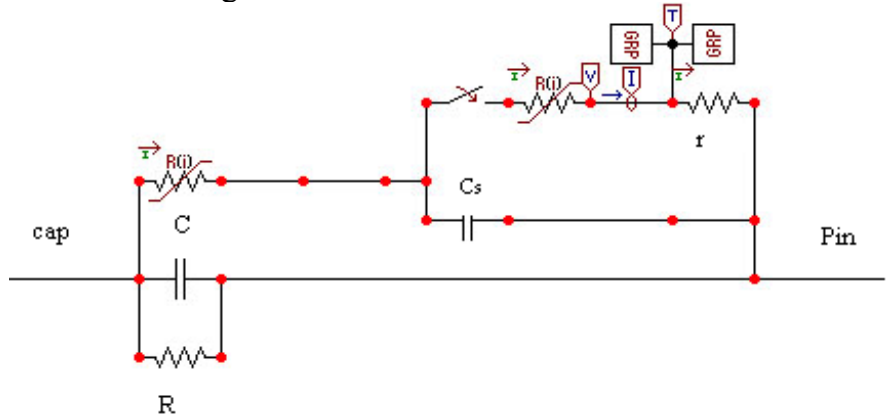

Figure 6. Equivalent circuit model of suspension high voltage insulator 
Using the equivalent circuit model, leakage current of suspension high voltage insulators were done using ATP/EMTP under several condition. The value of R is $4,4 \mathrm{G} \Omega$, while $\mathrm{C}$ is 5 $\mathrm{pF}$. The values are typical for a string insulator. The values of other parameters are dependent on the insulator surface condition such as the degree of pollution, the presence of RTV coating and other environmental conditions.

\section{Simulation results}

Figure 7 shows typical measured (a) and simulated (b) leakage currents for new-non coated insulator polluted at $25 \mathrm{mS} / \mathrm{cm}$ under clean fog under applied voltage of $10 \mathrm{kV}, 20$ $\mathrm{kV}$ and $45 \mathrm{kV}$ and corresponding V-I curve of the insulators obtained from the simulation (c). From the figure 7(a) it is clearly seen that LC waveforms are distorted. The LC magnitude was about $0.30 \mathrm{~mA}$ at applied voltage of $10 \mathrm{kV}$ and increased to about $1.1 \mathrm{~mA}$ and $1.9 \mathrm{~mA}$ under applied voltage of $30 \mathrm{kV}$ and $45 \mathrm{kV}$. The simulated leakage current waveforms depicted in figure 7(b) were obtained by using non linear resistor as shown in figure 5. The corresponding V-I curve is shown in figure 7(c). It is clearly seen that the surface resistance decreased as applied voltage increased. The V-I curve is non linear. The resistance values are named as $R_{1}, R_{2}, R_{3}, R_{4}$ and $R_{5}$ from low voltage to high voltage. The resistance values decreased from $R_{1}$ to $R_{5}$. This behaviour reflects the non sinusoidal form of the leakage current waveforms.

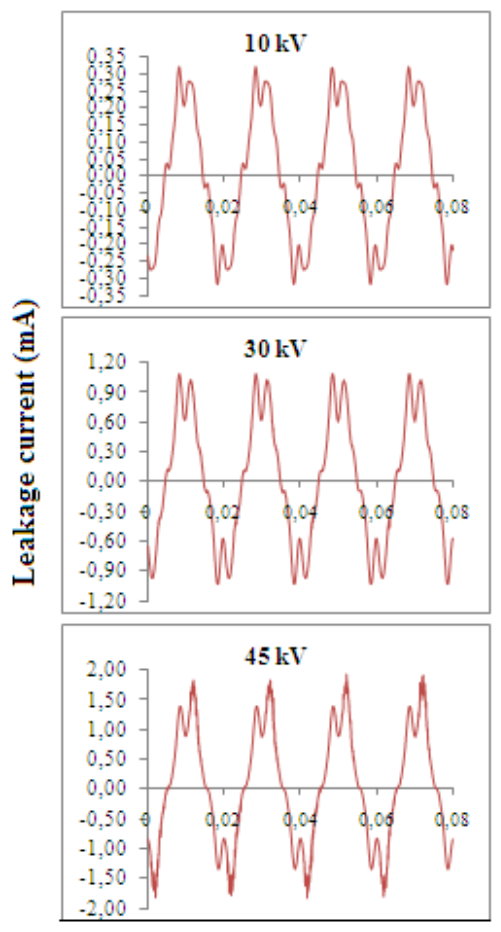

Time (s)

(a)
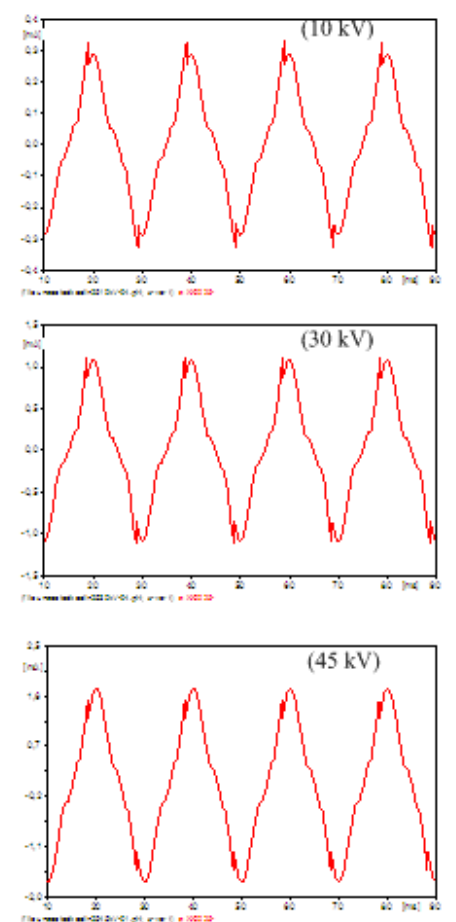

(b)

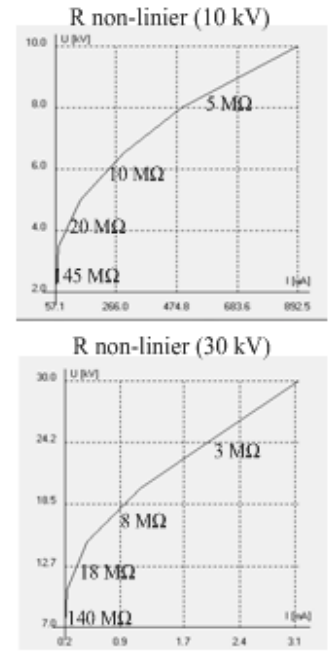

$\mathrm{R}$ non-linier $(45 \mathrm{kV})$

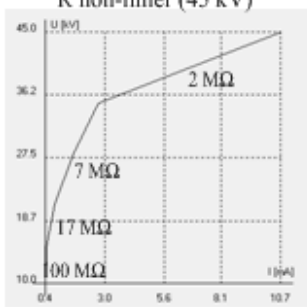

(c)

Figure 7. Typical measured (a) and simulated (b) leakage currents and (c) non linear resistors for non coated insulator polluted at $25 \mathrm{mS} / \mathrm{cm}$ under clean fog under applied voltage of $10 \mathrm{kV}, 20 \mathrm{kV}$ and $45 \mathrm{kV}$.

Figure 8 shows typical measured (a) and simulated (b) leakage currents for RTV coated insulators salt-kaolin polluted at $25 \mathrm{mS} / \mathrm{cm}$ under clean fog under applied voltage 
of $10 \mathrm{kV}, 20 \mathrm{kV}$ and $45 \mathrm{kV}$. The corresponding V-I Curve is shown in figure (c). It is clearly seen from measured LC waveforms that LC waveforms are distorted. The LC magnitude was about $0.35 \mathrm{~mA}$ at applied voltage of $10 \mathrm{kV}$ and increased to about $1.2 \mathrm{~mA}$ and $2 \mathrm{~mA}$ under applied voltage of $30 \mathrm{kV}$ and $45 \mathrm{kV}$. The LC magnitude was significantly lower than those of non coated insulator under clean fog (figure 7). The simulated leakage current waveforms depicted in figure $6(\mathrm{~b})$ were obtained by using non linear resistor as shown in figure (c).
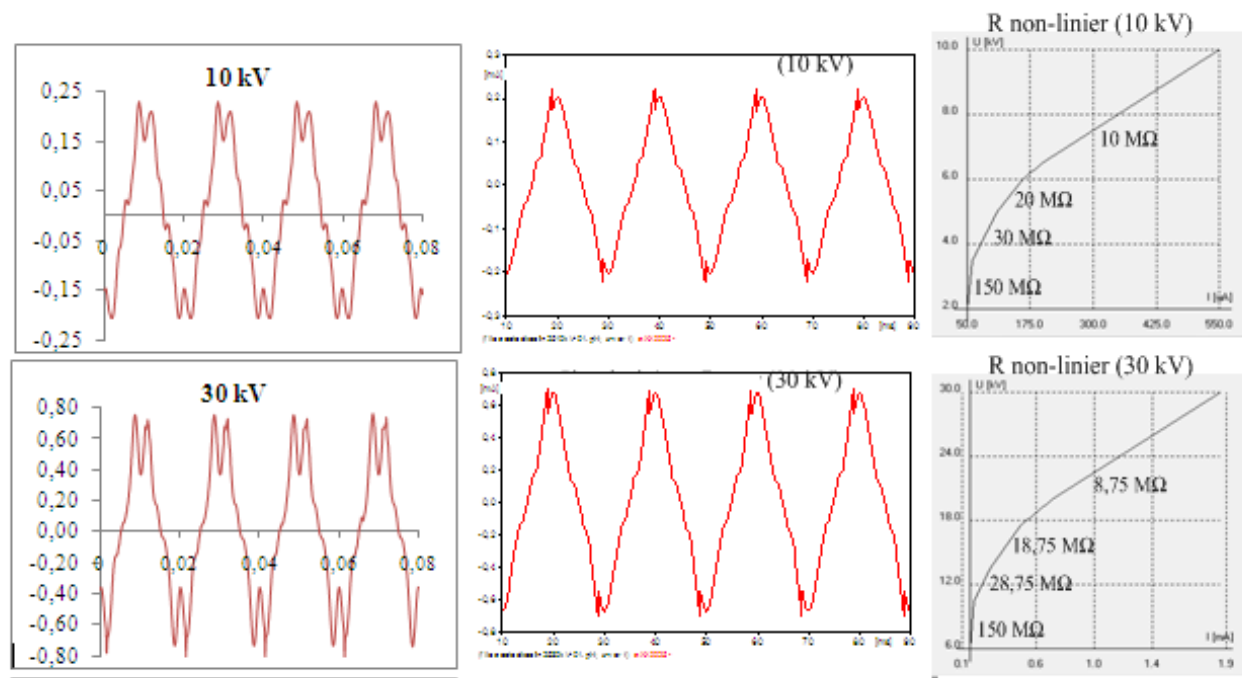

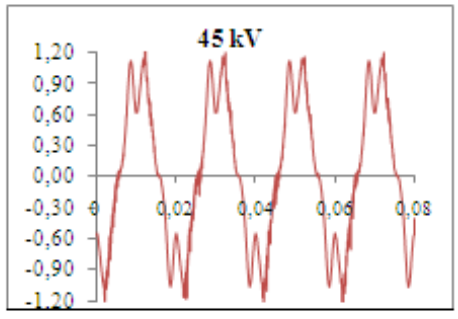

(a)

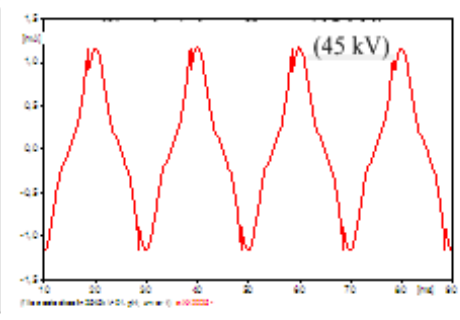

(b)

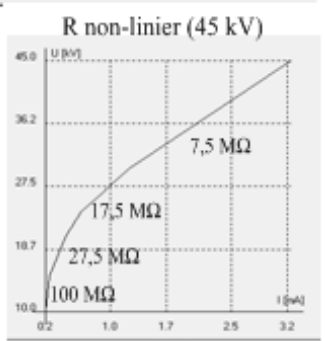

(c)

Figure 8. Typical measured (a) and simulated (b) leakage currents and (c) non linear resistors for RTV coated insulator polluted at $25 \mathrm{mS} / \mathrm{cm}$ under clean fog under applied voltage of $10 \mathrm{kV}, 20 \mathrm{kV}$ and $45 \mathrm{kV}$.

The non linearity behaviour of insulators under various conditions as indicated in V-I curves at $\mathrm{AC}$ voltage of $10 \mathrm{kV}$ are shown in table 3. The numerical values of the non linear resistances are shown in table 4. From the table it is clear that RTV coating significantly improves the non linear behaviour of outdoor insulator and increases the resistances. 
Table 3. V-I Curves of outdoor Insulators under various conditions

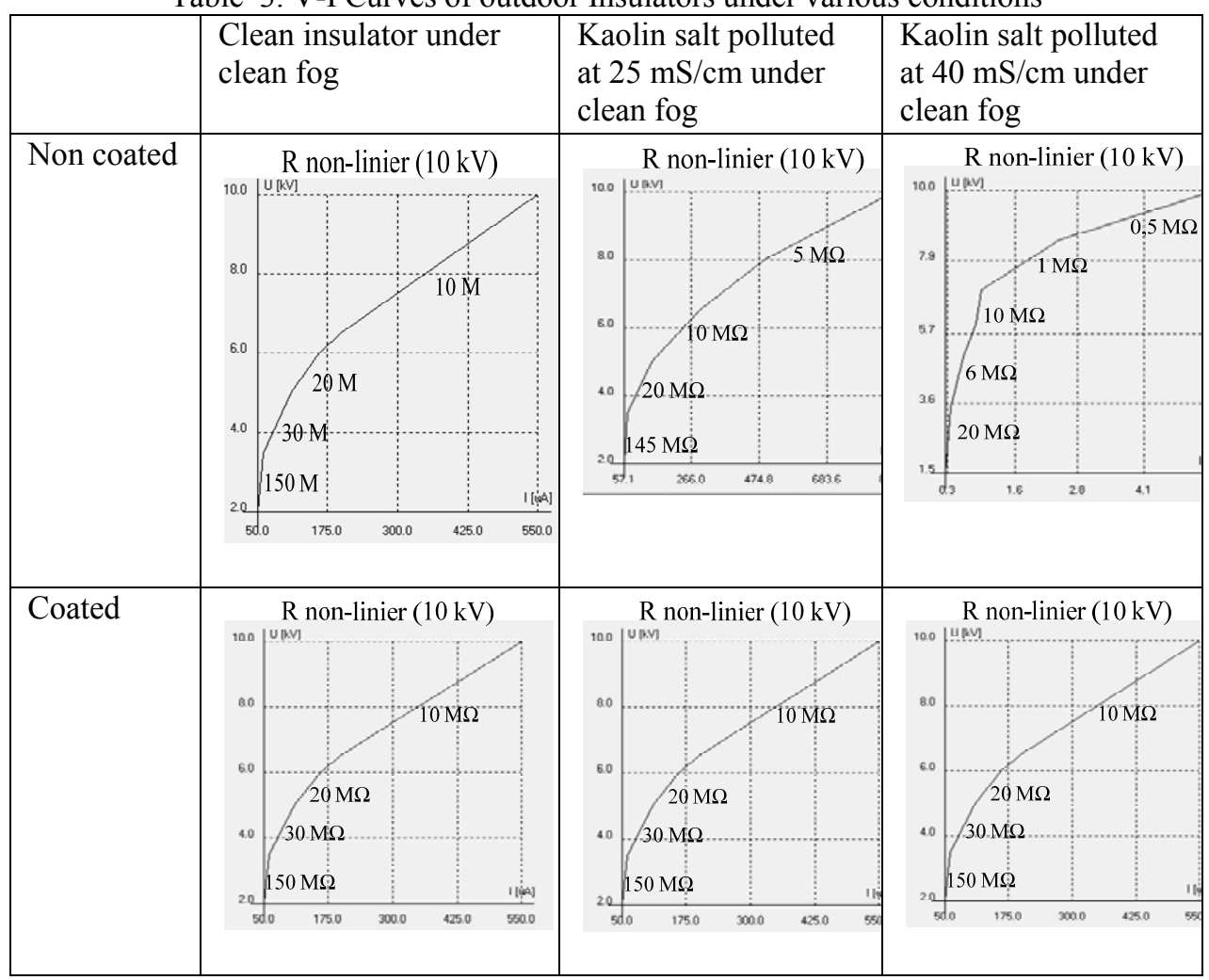

Table 4. Numerical values of Non Linear Resistances of Outdoor Insulators under various Conditions

\begin{tabular}{|c|c|c|c|c|c|c|}
\hline \multirow{2}{*}{$\begin{array}{l}\text { R Non- } \\
\text { linear }\end{array}$} & \multicolumn{3}{|c|}{ Non coated insulator } & \multicolumn{3}{|c|}{ RTV Coated insulator } \\
\hline & Clean & $\begin{array}{l}\text { Kaolin-salt } \\
25 \mathrm{~ms} / \mathrm{cm}\end{array}$ & $\begin{array}{l}\text { Kaolin-salt } \\
40 \mathrm{~ms} / \mathrm{cm}\end{array}$ & Clean & $\begin{array}{c}\text { Kaolin-salt } \\
25 \mathrm{~ms} / \mathrm{cm}\end{array}$ & $\begin{array}{c}\text { Kaolin-salt } \\
40 \mathrm{~ms} / \mathrm{cm}\end{array}$ \\
\hline $\mathrm{R} 1(\mathrm{M} \Omega)$ & 150 & 145 & 20 & 150 & 150 & 150 \\
\hline R2 (M $\Omega)$ & 30 & 20 & 6 & 30 & 30 & 30 \\
\hline R3 (M $\Omega)$ & 20 & 10 & 10 & 20 & 20 & 20 \\
\hline $\mathrm{R} 4(\mathrm{M} \Omega)$ & 12,5 & 7,5 & 1 & 12,5 & 12,5 & 12,5 \\
\hline R5 (M $\Omega)$ & 10 & 5 & 0,5 & 10 & 10 & 10 \\
\hline
\end{tabular}

\section{Conclusions}

We have investigated the properties of RTV silicone rubber coating for various types of outdoor insulators. From the investigation it is obvious that RTV silicone rubber coating improves the surface smoothness and hydrophobicity. RTV silicone rubber coated insulators can maintain their hydrophobicity under various polluted condition. RTV silicone rubber coating suppressed the magnitude of leakage current and increased the flashover voltage under various artificially - simulated pollution. RTV silicone rubber coating significantly reduces the corona intensity on the insulator surfaces. It also reduces the insulator surface temperature. 
From the electrical equivalent circuit model and computer simulation of leakage current waveforms it is clear that application of RTV silicone rubber coating increase the non linear resistances of the outdoor insulators.

\section{References}

[1] Gorur, R S, E A Cherney, and J T Burnham. Outdoor Insulators. Arizona: Ravi Gorur Inc, 1999

[2] Aydogmus, Zafer and Cebeci, Mehmet. A New Flashover Dynamic Model of Polluted HV Insulators, IEEE Trans.s on Dielectrics and Electrical Insulation, Vol. 11, No. 4, Agust, 2004.

[3] D.L. Williams, A. Haddad, A.R. Rowlands, H.M. Young, R.T. Waters, Formation and Characterization of Dry Bands in Clean Fog on Polluted Insulators, IEEE Trans. DEI, Vol. 6, No. 5, 1999, pp. 724-731.

[4] R. Water, A Haddad, H. Griffith, N. Haud, P. Sarkar, Partial arc and spark arc Models of the Flashover of Lightly Polluted Insulators, IEEE Trans. DEI, Vol. 19, No. 4, 2012, pp. 1318-1324

[5] H. Mei, L. Wang, G. Zhicheng, Y. Mao, Influence of Sugar as a Contaminant on outdoor Insulation Characteristics of Insulators in Substation, IEEE Trans. DEI, Vol. 17, No. 2, 2010, pp. 417-424

[6] IEC Pub. 507, Artificial Pollution Tests on High Voltage Insulators to be Used in ac System, 1991

[7] F. Bologna, N. Makatho, D. Hoch, Infra red and Ultra Violet Imaging Techniques Aplied to the Inspection of Outdoor Transactions Coltage Insulators, IEEE Africon 2002, pp. 593-598.

[8] Suwarno and P. Juniko, Effects of humidity and fog conductivity on the leakage current waveforms of ceramics for outdoor insulators, WSEAS Transactions on Systems, Volume 9, Issue 4, 2010, pp. 442-452

[9] Devendranath, Channakhesava, Leakage Current and Charge in RTV Coated Insulators under Pollution Conditions, IEEE Trans. DEI, Vol. 9, No. 2, 2002, pp. 294-299

[10] El Hag et. Al, Fundamental and low Freq. components of LC as a diagnostic Tool to Study Aging of RTV and HTV SIR in Salt-Fog, IEEE Trans. DEI, Vol. 10, No. 1, 2003, pp. 128- 136

[11] T. Tokoro, R. Hackam, Loss and Recovery of Hydrophobicity and Surface Energy of HTV Silicone Rubber, IEEE Trans. DEI, Vol. 8, No. 6, 2001, pp. 1088- 1097.

[12] H. Hilborg, U.W. Gedde, Hydrophobicity Changes in Silicone Rubber, IEEE Trans. DEI, Vol. 6, No. 5, 1999, pp. 703-717.

[13] T. Suda, Frequency Characteristics of Leakage Current Waveforms of an Artificially Polluted Suspension Insulator, IEEE Trans. DEI, Vol8, No. 4, 2001, pp. 705-

[14] Suwarno, Study on the wave form of leakage current on the $20 \mathrm{kV}$ post-pin ceramic insulators under various conditions, Proc. 2001 International Symp. on Electrical Insulating Materials (ISEIM 2001), Himeji, Japan, 2001, pp. 387-390

[15] M.Otsubo, T. Hashiguchi, O. Takenouchi, T. Sakoda, Y. Hashimoto, Evaluation of Insulation Performance of Polymeric Surface using a Novel Separation, IEEE Trans. on DEI, Vol. 10, Issue 6, 2003, pp. 1053-1060

[16] Suwarno, Fari, Electrical Equivalent Circuits of Outdoor Insulators based on Leakage Current waveforms and Computer Simulation, 9 th IEEE Int. Conf. on Properties and Appl. Of Dielectric Materials, Harbin, 2009 , pp. 138-141 


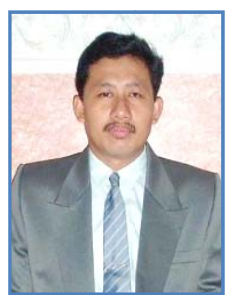

Suwarno was born in Indonesia in 1965. He received BSc and MSc from The Department of Electrical Engineering, Bandung Institute of Technology, Bandung, Indonesia in 1988 and 1991 respectively. He received $\mathrm{PhD}$ from Nagoya University, Japan in 1996 in the field of High Voltage Electrical Insulation. Suwarno is a professor in The School of Electrical Engineering and Informatics Institut Teknologi Bandung and currently he is the Dean of the School. Suwarno is a member IEEE.

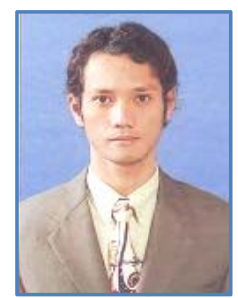

Ario Basuki Wibowo received the B.S. and M.S. degree in electrical power engineering from Bandung Institute of Technology in 2007 and 2010 respectively. He joined Medco E\&P Indonesia Company in 2011 and currently work there as an Electrical Engineer. 